\title{
Food Traceability System Tending to Maturation in China
}

\author{
Fengyun Wang ${ }^{1, *}$, Jianhua Zhu ${ }^{1}$, Minghua Shang ${ }^{1}$, Yimin $Z_{h a o}{ }^{2}$, and Shuyun Liu ${ }^{1}$ \\ ${ }^{1}$ S\&T Information Engineering Research Center, \\ Shandong Academy of Agricultural Sciences, Jinan 250100, \\ Shandong Province, P.R. China, \\ Tel.: +86-531-83179076; Fax: +86-531-83179821 \\ wfylilya163.com \\ ${ }^{2}$ Quality Assure Department, Shandong Shengli CO., Ltd., Jinan 250101 China
}

\begin{abstract}
The study on food safety traceability system in China started from 2002. During the study and implementation, some related standards and guides have been gradually made, many traceable foods and traceable enterprises were created and a series of traceability subsystems were developed. This paper introduces the importance of food safety traceability system construction, the present construction situation in China and the food safety traceability platform by bar code, deeply analyzes the existing problems and puts forward some advices. It shows that a sound food traceability system has been built in China and tends to maturate. It provides the reference for food safety traceability system construction in developing countries.
\end{abstract}

Keywords: Food safety, Traceability, China.

\section{Introduction}

In recent years, there have been many problems in food safety from mad cow disease and foot-and-mouth disease (FMD) in foreign country to water injected meat, inferior milk powder and Sudan red event in China which has been attracted the attention of the world (Li, G. et at., 2007). Food safety has been the concerned issues by the consumers and the businessmen together and become the important factor that affected the international competitiveness of Chinese agriculture and food industry.

As the biggest developing country and WTO membership country, China actively coped with various food problems, carried out the preliminary study on food safety traceability, made some related standards and guides, preliminarily created some food traceability institutions and issued some regulations in some local governments and enterprises. Article Numbering of China (ANCC) cooperated with China National Food Industry Association (CNFIA) to build the food safety traceability platform by bar code, establish a great deal of traceable foods and enterprises and develop a series of traceability subsystem (Chen, H. et at., 2007).

\footnotetext{
${ }^{*}$ Corresponding author.
} 
Food safety traceability system (FSTS) is referred to an information management system that can connect the production, inspection, supervision and consumption etc processes to let the consumers know about the sanitary and safe production and circulation process and improve the safety trust of consumers on the food (MchKean, J.D. 2001). FSTS provides the traceability mode "from farm to table", selects some common traceable factors concerned by the consumers from production, processing, circulation and consumption etc supply chains, creates food safety information database, once there is food safety problem, it can effectively control and call back the food according to the traceability so as to ensure the legal rights and interests of consumers from the food source (Huang, W. et at., 2006). Fig.1 is the diagram of FSTS

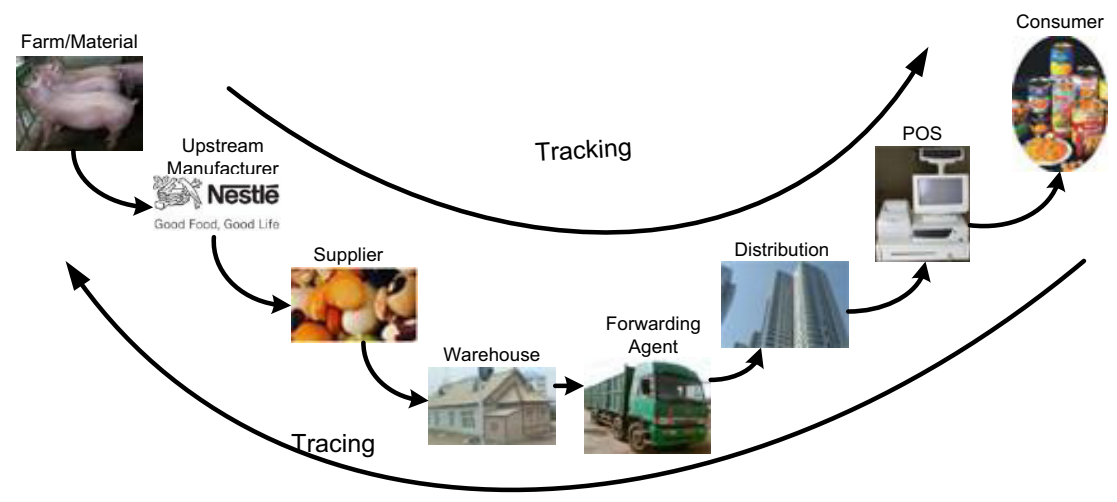

Fig. 1. Food Safety Traceability System

\section{Importance}

\subsection{FSTS Is Necessary for Ensuring the Food Safety}

With the improvement of living standard of consumers and the arising of food safety problems, food safety is increasingly concerned by every country in the world.

From domestic environment, facing the frequently happened food safety accidents, the consumers hope to know about the whole process of food production and circulation. In order to meet the consumers' requirements, enhance the consumers' trust on the food, food enterprises and food industries, build a well-off society in all around way, improve the living quality of the people and reduce the economic and social efficiency loss caused by food safety accidents, it is necessary to build the FSTS.

From international environment, European Union (EU) and America etc developed countries and areas require that some imported foods must have the traceability requirement. The EU administration statute No. 178/2002 requires that all meat sold within EU areas must be tracking and traceable since Jan., 1st, 2005, or else can't be sold in the market (Guan, E. et at., 2006). Japan decided to build good agricultural products certification system before 2005 to certificate the identity of agricultural products into the Japanese market (Ozawa Y et al., 2001). The FSTS built by the developed country plays increasingly obvious trade barrier role, except that it can effectively ensure the food safety and food traceability. 
Therefore the FSTS not only provides the safe food with high quality for the people, but also breaks the trade barrier caused by the food safety traceability which plays important role for improving the international competitiveness of Chinese agricultural products (Qiao, J. 2007).

\subsection{FSTS Is an Effective Means to Control the Food Quality}

FSTS has been one of the key factors to study and make the food safety policy. ISO 9000, GMP, SSOP and HACCP etc many effective management measures have been introduced to control the food safety and achieved a certain effect in the practice ( $\mathrm{Lu}$, C. et at., 2006). But the above mentioned measures are mainly for processing chain and lack the means to connect the whole supply chain.

The traceability system emphasizes the unique mark of product and the whole process tracking, for traceable food, it can track and trace the product information of each process on the whole supply chain by HACCP, GMP or ISO9001 etc quality control methods, once there is food safety problem, it can effectively track the source of the food and timely call back the unqualified product to minimize the loss.

\subsection{FSTS Is Helpful to Overcome the Information Asymmetry}

The characteristic of experiential food and trustful food makes the information asymmetry among the producer, businessman, consumer and even the government, the details are: (1) the food safety character is the inner character and difficult to identify from the appearance for the consumer which make the safety information asymmetry among the producer, businessman and consumer. (2) Though the government etc supervisors can measure the food safety level, under small-scale peasant economic regime, the food has distributed production site, wide area and large quantity and lacks the mark, the food safety responsibility traceability is bad and the measure cost is high and speed is low which greatly improve the supervising cost. In addition, for a long time, China partly pursues the amount and commercial character of food and lacks the sound and effective food safety supervising regulation and means which lead to the safety information asymmetry among the governmental supervisor, producer and businessman. (3) The food safety information from government etc supervisors can't be quickly and effectively sent to the consumers which lead to the safety information asymmetry between the government and consumer so as that the consumer lacks the information for selection. (4) The food safety information between the top supervisor and the bottom supervisor is different and can't be completely shared and communicated which lead to the safety information asymmetry between the top supervisor and bottom supervisor (Qiao, J. 2007).

\section{Present Construction Situation of FSTS in China}

\subsection{Established Some Related Regulation and Standard}

The study on food traceability system in China started from 2002 and gradually made some related standards and guides. For example, in order to respond to implement the aquatic products trade traceability from 2005 in EU, the General Administration of Quality Supervision, Inspection and Quarantine of the People's Republic China drew 
up «Traceability regulations for emigrated aquatic products (try out) », ANCC made «Traceability guide for beef products» on the base of the experience of EU. Shaanxi Standardization Academe made «Applicable scheme of quality tracking and traceability system for beef products» (Chen, H. et al., 2007).

Some local governments and enterprises built the traceability regime of some food and issued some rules. In Jul., 2001, Shanghai city government issued «Temporary methods of safety supervision for edible agricultural products in Shanghai» and put forward that created "market archives traceability system" on circulation chain. In 2002, Commerce Committee of Beijing City established the food information traceability system to clearly require that the food businessman should have subsidiary ledger for purchased and sold foods i.e. the purchased food should be created the archives of origin, supplier, purchased date and batch. On Sept., 20th, 2005, Shunyi District firstly launched the graded package and quality traceability regime for vegetable in Beijing City. In order to ensure the citizen purchase the reliable non-pollution vegetable, Tianjin City carried out non-pollution vegetable traceability regime and launched non-pollution vegetable order service on the internet.

\subsection{Built the Food Safety Traceability Platform by Bar Code}

ANCC cooperated with CNFIA to build the food safety traceability platform by bar code, through the platform, established a great deal of traceable foods and enterprises and develop a series of traceability subsystem. The platform framework is shown in Fig.2 (Yang X. et al., 2006).

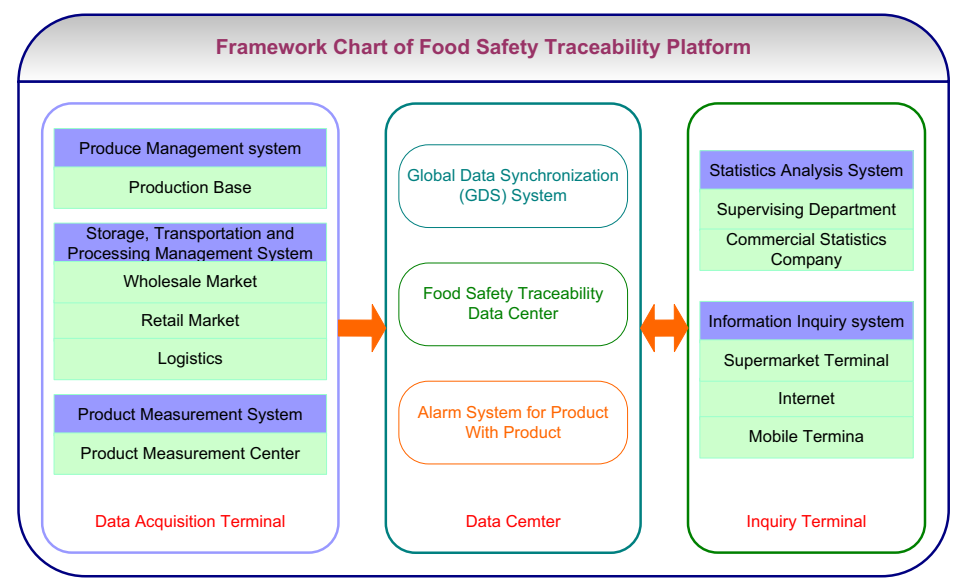

Fig. 2. Framework Chart of Food Safety Traceability Platform

\subsubsection{Established a Great Deal of Traceable Foods}

As of present time (Feb., 26th, 2008), through the platform, there have established 10362 meet and poultry products, 12323 fruits, vegetables, nuts and seeds, 2686 sea products, 8433 dairy products and eggs, 5028 edible oil and grease, 7322 chocolate, sugar, sweet products and candies, 20427 flavorings and preservatives, 12150 bread and baking foods, 27769 prepare instruments and cans, 40028 beverages, 349 tobacco 
and its products, 6185 grain and legume products, 4348 others and the numbers of traceable foods are increasing.

The basic information of these traceable foods includes: global trade item number (GTIN), main picture, global location number (GLN), Chinese name of product, English name of product, Chinese name of trademark, English name of trademark, specification, classification, aimed market, package mode code, height, width, depth, shelf life, origin, marketing time, keyword, short description of product, package material etc, in addition, also includes additional information, extended information and multimedia information. The manufacturer information of the product can be traced by the system, including company introduction, main product or service, main business place, management system certification, business trademark, enterprise name (Chinese), enterprise name (English), registered address (Chinese), registered address (English), registered postcode, business place (Chinese), business place (English), business postcode, contact, telephone, fax, email and enterprise website etc.

\subsubsection{Established a Great Deal of Traceable Enterprises}

As of present time (Feb., 26th 2008), based on the global data synchronization (GDS), there have established 250 enterprises for planting and cultivation, 6194 enterprises for manufacturing the agricultural and sideline products, 2984 enterprises for manufacturing the baking food, 2075 enterprises for manufacturing the prepare food and can, 519 enterprises for manufacturing the dairy product, 1519 enterprises for manufacturing the health food, 179 enterprises for manufacturing the additive, 2643 enterprises for manufacturing the alcoholic liquor, 2169 enterprises for manufacturing the beverage, 32 enterprises for manufacturing the tobacco, 937 enterprises for manufacturing the pesticide and pharmaceuticals, 883 enterprises for bulk and retail selling the food pharmaceuticals and 1835 other food enterprises and the numbers of traceable enterprises are also increasing.

GDS is a key project of ECR (Efficient Consumer Response) committee. At present, America and European are implementing the synchronization between GDSmerchandise database and the merchandise database of retailer and manufacturer, including Wal-Mart and the large scaled manufacturer in America, and it has obtained a certain effect. In Asia, Korea also established this system which data pool included more than 10,000 merchandise information over 200 suppliers and made the speech and demonstration on ECR Expo in Asia in Oct., 2003.

In China, in order to create the content database (data pool) and data synchronization system of electronic merchandises in quick circulation consumable industry (retailer and manufacturer) in China, ANCC is actively carrying out the study of global data dictionary (GDD) and global product classification (GPC) and internationally has signed with UCC to take charge of the maintenance of UNSPSC standard (Chinese version) and signed with EAN to take charge of the Chinesization of GDD and the registration, management, maintenance and standard establishment of domestic EPC system.

\subsubsection{Developed a Series of Traceability Subsystem}

China has made preliminary experiments on food traceability system and developed a series of traceability subsystem. In 2004, the vegetable quality safety traceability system is tried out on Shouguang Tianyuan Vegetable Base and Luocheng Vegetable Base under the cooperation of General Administration of Quality Supervision, Inspection and Quarantine of the People's Republic China, Weifang City and Shouguang 
City Bureau of Quality and Technical Supervision in Shandong Province together. ANCC promotes the application of bar code technology in food traceability in China through the China bar code promotion project and successively carried out the food traceability technology study and try-out in Shaanxi, Beijing, Shanghai and Shandong etc places, e.g. "Agricultural products inquiring system In Shanghai City", application and demonstration system of tracking and traceability automatic identification technology for beef product in Beijing Jinweifuren Hala Food Co., Ltd and fruit traceability information system in Jiangxi, Olympic FSTS etc.

In July, 2005, Beijing Municipal Government began to launch the action plan for the Olympic green food engineering program and supervised, aiming for every section involving with production, processing, transportation, storing, packaging, testing and hygiene. The solution of Olympic FSTS mentioned by Aerospace Golden Card Company has been adopted. Olympic FSTS will be used in "Lucky Beijing" sports competition. It includes fruit \& vegetable, animal, pre-packaged food and Olympic foods four subsystems, covering the main food varieties and planting, cultivation, production and manufacturing and logistics etc processes of Olympic foods. The related material producer and supplier of food and beverage and food and beverage service unit will be recorded in the system. No matter what process, from the farm and athlete table, and no matter what food have problem, from aquatic products, livestock, poultry to fruit and vegetable products, it can be found out.

\section{Main Problems}

On Apr., 13th, 2007, China Chain-Store \& Franchise Association (CCFA) released «Study report about food safety traceability» in Beijing. It indicated that China faced six great obstacles to establish FSTS as following:

(1) In China, the production of food, especially agricultural product, is quite distributed, the intensive degree of production is not high, the technology and standardization level is low; (2) The circulation mode of food is backward, the traditional circulation channels, e.g. wholesale market and bazaar, occupy great proportion, the modern circulation channel, e.g. chain-supermarket, isn't popular; (3) Food safety law system and standard system aren't sound, related regulations and standards lack and lag behind the actual development and there are many cases that can't meet the international standard; (4) The systematicness and unity of food safety supervising regime isn't still enough; (5) The whole social cognition about FSTS isn't sufficient; (6) The cost for creating the traceability system is higher and the enterprise lacks the prior devoted drive (http://www.tech-food.com/news/2007-4-16/n0105260.htm).

\section{Advice}

According to the construction situation in China and the main problems, the FSTS construction should be perfected and improved from the following aspects:

(1) The laws, regulations and policies related to the food safety should be perfected to provide the system guarantee for implementing the food safety traceability; (2) The supervising regime of food safety traceability should be harmonious and a relatively 
centralized and uniform professional supervising regime should be established to provide the regime guarantee for implementing the traceability; (3) The related sound standard system should be constructed to provide the technology basis for implementing the traceability; (4) Promote the construction of agricultural products etc food production base, advance the product quality level and optimized the food supply chain; (5) The role of modern circulation modes represented by the chain supermarket in implementing the traceability should be enough exerted; (6) Use the chance of food safety cared by all societies to stress the propaganda of related traceability knowledge and create the social foundation of implementing the traceability; (7) Stress the traceability technology study and provide more convenient and cheaper technology; (8) Construct demonstration projects of food safety traceability to provide the reference and promote the application (Zou, Y. et at., 2005).

\section{References}

[1] Li, G., Huang, L., Zhan, J., et al.: RFID Application in Food Safety Traceability. Logistics \& Material Handing 12(3), 85-87 (2007)

[2] Chen, H., Tian, Z.: Comparative Study of Traceability System on Domestic and Foreign Agricultural Products. Market Modernization (7X), 5-6 (2007)

[3] MchKean, J.D.: The Importance of Traceability for Public Health and Consumer Protection. Scientific and Technical Review 20(2), 363-371 (2001)

[4] Huang, W., Wang, M., Zheng, Z., et al.: Create Modern Animal and Animal Products Identification and Traceability System. China Journal of Animal Quarantine 23(11), 1-4 (2006)

[5] Guan, E., Zhang, Y.: Studies on Implementation of Food Traceability Management. Chinese Journal of Food Hygiene 18(5), 449-452 (2006)

[6] Xu, S., Li, Z., Li, Z.: Study on China Food Safety Informaiton Sharing and Public Management System. China Agriculture Press, Beijing (2006)

[7] Ozawa, Y., Ong, B.L., An, S.H.: Traceback Systems Used During Recent Epizootics in Asia. Scientific and Technical Review 20(2), 605-613 (2001)

[8] Qiao, J., Han, Y., Li, D.: Importance and Restricting Factor Analysis on Implementing Food Safety Traceability in China. Guide To Chinese Poultry 43(6), 10-12 (2007)

[9] Lu, C., Xie, J., Wang, L., et al.: Completion of Digital Tracing System for the Safety of Factory Pork Production. Jiangsu Journal of Agricultural Sciences 22(1), 51-54 (2006)

[10] Wang, L., Lu, C., Xie, J., et al.: Review of traceability system for domestic animals and livestock products. Transactions of the CSAE 21(7), 168-174 (2005)

[11] Yang, X., Qian, J., Sun, C., et al.: Implement of Farm Product Archives Management System Based on Traceability System. Chinese Agricultural Science Bulletin 6(6), 441444 (2006)

[12] Bai, Y., Lu, C., Li, B.: Design of Traceability System for Broiler Secure Production Monitoring. Jiangsu Journal of Agricultural Sciences 21(4), 326-330 (2005)

[13] Vitiello, D.J., Thaler, A.M.: Animal Identification: Links to Food Safety. Scientific and Technical Review 20(2), 598-604 (2001)

[14] Zou, Y., Jin, X.: Problems and Countermeasures Analysis in Food Safety Management. Chinese Health Quality Management 12(5), 57-59 (2005)

[15] Tech-food.com (2007)-Study Report about Food Safety Traceability website, http: / /www . tech-food.com/news/2007-4-16/n0105260.htm (document accessed on April 16, 2007) 